Cadernos de História, Belo Horizonte, v. 22, n. 37, Novembro de 2021

DOI: https://doi.org/10.5752/P.2237-8871.2021v22n37p53-67

\section{MEMÓRIAS DE UMA VIDA DEDICADA AO ESTUDO DAS MULHERES NO ESPORTE: ENTREVISTA COM SILVANA Vilodre GoEllner}

Nivalda Pereira Coelho Universidade Estadual do Sudoeste da Bahia nyvia.uneb@outlook.com

Felipe Eduardo Ferreira Marta Universidade Estadual do Sudoeste da Bahia fefmarta@gmail.com

\title{
RESUMo
}

O objetivo deste estudo foi analisar a trajetória de vida da professora Silvana Goellner, a partir de uma entrevista realizada na cidade de Alagoinhas - BA, no dia 25 de outubro de 2019. A metodologia utilizada foi pautada na história oral, visto que possibilita um maior aprofundamento dos aspectos que marcaram a vida da entrevistada. Esses aspectos foram apresentados no decorrer deste trabalho em três momentos: (I) contextos e possibilidades da infância; (II) processo de formação acadêmica; (III) contribuições para o estudo sobre mulheres. Algumas situações vivenciadas na sua infância, como a aproximação com os esportes e a figura marcante da mãe enquanto uma mulher de luta, refletiram significativamente ao longo da sua vida, direcionando e vinculando suas escolhas acadêmicas e profissionais aos aspectos sociais. Foi possível entrelaçar os fragmentos de uma memória individual da entrevistada com memórias oficializadas perante a sociedade e que foram determinantes para sua atuação acadêmica e científica. Seu pioneirismo nas discussões sobre mulheres no esporte, bem como sua história de vida enquanto mulher e pesquisadora deixaram um legado que contribui diretamente para o campo da Educação Física, se tornando referência nesses estudos, ao registrar e dar visibilidade aos processos de luta das mulheres no esporte.

Palavras-chave: Memória; Mulheres; Esporte; História Oral.

Recebido em 27 de novembro de 2020.

Aprovado em 15 março de 2021. 
Cadernos de História, Belo Horizonte, v. 22, n. 37, Novembro de 2021

DOI: https://doi.org/10.5752/P.2237-8871.2021v22n37p53-67

\section{MEMORIES OF A LIFE DEDICATED TO THE STUDY OF WOMEN IN SPORT: INTERVIEW WITH Silvana Vilodre Goellner}

Nivalda Pereira Coelho Universidade Estadual do Sudoeste da Bahia nyvia.uneb@outlook.com

Felipe Eduardo Ferreira Marta Universidade Estadual do Sudoeste da Bahia fefmarta@gmail.com

\begin{abstract}
This study aims to analyze the life history of Professor Silvana Goellner, starting with an interview which took place in the city of Alagoinhas - BA, on October 25th, 2019. The methodology used was based on oral history, as it allows thoroughly check the aspects that marked the interviewee's life. These aspects were presented during this work in three moments: (I) contexts and possibilities of childhood; (II) academic training process; (III) contributions to the study of women. Some events experienced in her childhood, such as the involvement in sports and the marking figure of her mother as a struggling woman, reflected significantly throughout her life, directing and linking her academic and professional choices to social aspects. It was possible to link the fragments of an individual memory of the interviewee to official memories before society which were a determining factor in her academic and scientific performance. Her pioneering role in discussions about women in sport has left a legacy that contributes directly to the field of Physical Education, becoming a reference in these studies by recording and making women's struggle notable in the sports.
\end{abstract}

Keywords: Memory; Women; Sport; Oral History. 


\section{INTRODUÇÃo}

O surgimento de uma história exclusivamente das mulheres ainda é muito recente, surge em meados da década de 1960, devido a influências de fatores científicos, sociológicos e políticos (PERROT, 2019). Para que essa história seja escrita, faz-se necessário o uso de fontes, documentos ou algo que ajude nesse processo; isso, muitas vezes, não é possível pelo fato de essas fontes não existirem, pois não foram registradas ou simplesmente foram apagadas ao longo das circunstâncias de convívio em sociedade (PERROT, 2019).

Contudo, os estudos sobre o protagonismo das mulheres na sociedade têm sido intensificados e muitas pesquisas ${ }^{1}$ surgiram com a finalidade de dar visibilidade à presença feminina, principalmente no meio esportivo, um espaço que por muito tempo foi negado a elas. Grosso modo, é possível inferir que, culturalmente, o meio esportivo têm evidenciado a participação e o desempenho masculino em detrimento do feminino, uma realidade que pode ser entendida no bojo de um processo maior de invisibilização na sociedade.

Um exemplo emblemático da diferença de tratamento dado à mulher no esporte pode ser verificado no estudo de Oliveira (2008) ao tratar da influência midiática. De acordo com a autora, a mídia, na maioria das vezes, não se interessa em transmitir o meio esportivo em que a mulher está inserida, nem mesmo nas modalidades em que elas têm destaque mundial. Essa situação se justificaria pelo fato de o esporte ter a imagem de ídolo vinculada aos homens.

No contexto brasileiro - em relação à presença e protagonismo das mulheres no esporte - é possível verificar também um aumento significativo no número de pesquisas sobre o assunto, e nesse espectro, destacam-se alguns nomes, entre eles o da professora e pesquisadora Silvana Vilodre Goellner ${ }^{2}$.

Recentemente aposentada em sua atividade como docente da Universidade Federal do Rio Grande do Sul (UFRGS), Goellner, no entanto, ainda atua como ativista e pesquisadora sobre o tema das mulheres no esporte e na Educação Física. A professora pode ser considerada uma das precursoras dos estudos relacionados às mulheres no Brasil, principalmente no meio esportivo. Com uma história de vida marcada pela influência da figura materna, a trajetória acadêmico-profissional de Silvana Goellner sempre esteve vinculada aos esportes e à presença feminina nesse espaço.

Assim, o objetivo do presente estudo foi analisar elementos da trajetória de vida dessa professora, tendo como fonte uma entrevista concedida por ela na cidade de Alagoinhas - BA, no dia 25 de outubro de 2019. Especificamente, buscou-se, partindo da memória dessa personagem, identificar os momentos que marcaram sua vida; abordar sua escolha profissional e seu engajamento acadêmico e político; por fim, relacionar esses elementos ao contexto histórico da Educação Física e com o campo científico e social direcionado ao estudo de mulheres no esporte brasileiro.

A abordagem utilizada foi pautada na história oral, entendida enquanto uma

1 Cf. Goellner e Ramos (2018); Moraes (2012); Kessler, Costa e Pisani (2020); Goellner e kessler (2018); Altmann e Fernandes (2014).

2 Silvana Vilodre Goellner nasceu na cidade de Carazinho no Rio Grande do Sul. É licenciada em Educação Física pela UFSM, mestre em Ciências do Movimento Humano pela UFRGS, doutora em Educação pela UNICAMP e PósDoutora pela Faculdade do Desporto da Universidade do Porto (Portugal). Aposentou-se no cargo de professora titular da Universidade Federal do Rio Grande do Sul em maio de 2019. Goellner relata sua história de vida, abordando, em sua fala, momentos marcantes da sua trajetória. 
metodologia de pesquisa e também de constituição de fontes que podem ser utilizadas no estudo da história contemporânea. Através desse método, é possível que haja um maior aprofundamento investigativo a partir dos momentos que marcaram a vida das personagens históricas, relacionando-os com outros fatos e acontecimentos sociais contidos em fontes de outra natureza, em especial, mas não exclusivamente, as escritas (ALBERTI, 2005).

Os estudos baseados nessa metodologia de pesquisa possibilitam ao pesquisador um contato diferenciado com a história, isso porque se utiliza da memória enquanto meio para chegar aos resultados. Para Bosi (2003), através das fontes orais, muitas classes silenciadas pela história oficial tomam a palavra, podendo expor individualidades, pontos de vistas contraditórios e perfis culturais, tais como usos e costumes, aspectos que a história baseada em documentos oficiais muitas vezes não consegue alcançar.

A partir de elementos presentes na entrevista com Goellner, concomitantemente a referências contextuais dos momentos citados por ela, foram discutidos aspectos relacionados a sua formação acadêmico-científica e as questões de gênero na Educação Física. Nesse sentido, o presente artigo está divido em três momentos. Inicialmente, fizemos uma breve apresentação sobre o contexto e as possibilidades que marcaram a infância da professora. Em seguida, foram abordadas as discussões que envolveram a Educação Física durante sua formação acadêmica e, posteriormente, falamos sobre a importância e a contribuição da sua trajetória para o estudo das mulheres. Por fim, tecemos as considerações finais do presente estudo.

\section{“EU SEMPRE TIVE UMA INFLUÊNCIA ESPORTIVA": CONTEXTOS E POSSIBILIDADES DA INFÂNCIA de Silvana Goellner}

Silvana Vilodre Goellner nasceu em 1963, na cidade de Carazinho, no Rio Grande do Sul (RS), onde passou toda sua infância. No ano de 1982, mudou-se para Santa Maria, no mesmo estado, onde cursou Educação Física na Universidade Federal de Santa Maria (UFSM). Ingressa no mestrado da Universidade Federal do Rio Grande do Sul (UFRGS) e, assim que defende sua dissertação em 1992, sai o resultado de aprovação no concurso que prestou para essa mesma instituição. No ano de 1993, muda-se para Porto Alegre - RS e começa a atuar como docente na Escola Superior de Educação Física (ESEF) da UFRGS, onde permanece até a sua aposentadoria no ano de 2019.

Em meados de 1968, aos cinco anos de idade, sofreu a perda do pai em um acidente aéreo. Isso ocorreu devido a uma falha técnica que provocou a queda do avião pilotado por ele, causando uma grande tragédia para a população de Porto Alegre na época. O episódio traumático serviu para fortalecer os laços entre Silvana Goellner e sua mãe, que, a partir desse momento, assumiu as responsabilidades diante da desestruturação familiar. A figura da mãe em sua vida teve um significado muito marcante, de garra e determinação, despertando sua atenção para as questões que lhes dizem respeito. No período em que houve a tragédia com seu pai, tiveram o suporte dos avós, já que as circunstâncias da mãe não eram tão favoráveis - estava com duas crianças pequenas e grávida da terceira.

Primogênita e única mulher entre os três irmãos, Silvana traz em seu relato a imensa alegria vivenciada na infância, na companhia deles. Uma infância típica de cidade pequena, 
em que havia bastante tempo para brincadeiras, na maioria das vezes, relacionadas a esportes como a natação, futebol, pingue-pongue e voleibol. Isso fez com que ela estivesse sempre ligada ao esporte, como pode ser observado em seu relato: "Eu sempre tive uma influência esportiva [...] a gente jogava junto assim, jogava de tudo um pouco, então eu sempre tive uma vida muito esportiva"3.

Em sua entrevista, percebe-se que as relações estabelecidas com o meio esportivo durante toda a infância foram cruciais para suas escolhas na vida adulta, buscando sempre maiores aproximações com as atividades que envolviam suas práticas cotidianas com grupos de amigos.

As referências de Silvana quanto aos anos em que estava no ensino básico denotam o perfil de uma aluna muito presente na escola e isso ela justifica ao fato de a cidade ser muito pequena. Mesmo tendo aulas apenas em um turno, voltava no turno oposto para auxiliar os professores, como uma espécie de aluna voluntária. Algo que fazia muito nessas situações era participar dos times de outras turmas, principalmente voleibol, que embora ela gostasse muito de jogar, não havia times femininos, por isso sempre jogava com os meninos. Ao questionarmos a presença de preconceitos ou algo do tipo ela relata:

Não! Porque não tinha interesse. De handebol tinha feminino, mas de voleibol, que era o que eu jogava, não tinha. E quando tinha não era tão potente como eu queria que fosse. Como eu jogava, eu sempre fui muito alta jogava sempre com os meninos. ${ }^{4}$

Outra lembrança marcante para Silvana foram as idas ao clube da cidade para nadar com o seu grupo de amigos. Passavam o dia todo sem ir em casa nem para almoçar, já que levavam as marmitas exatamente para aproveitar mais o tempo. Ao longo do seu depoimento, nota-se que essa relação construída com os esportes ajudou a criar uma inclinação para a atuação em projetos de extensão universitária durante a graduação.

No término do segundo grau, ${ }^{5}$ ainda em Carazinho, nossa entrevistada realiza a sua escolha profissional, decide ingressar na Universidade e começa a cursar Letras na UFRGS, sua intenção inicial era se tornar Tradutora Intérprete. No entanto, no primeiro ano de curso notou que não era bem aquilo que queria, que poderia estudar inglês fora do país em outro momento. Como sempre foi muito livre para fazer suas escolhas, decidiu mudar para o curso de Educação Física, inicialmente na cidade de Passo Fundo, próxima a Carazinho, e, posteriormente na Universidade Federal de Santa Maria (UFSM), que na época era referência nesse curso curso. Por fim, realizou novamente o vestibular e ingressou na turma de 1982 .

Os anos da graduação, mais especificamente os vivenciados como discente do curso de Educação Física da UFSM, foram cruciais para sua formação social e política, já que foi nesse período que Silvana teve contato com o diretório acadêmico da universidade e pôde fazer parte de organizações e movimentos que nele eram desenvolvidos.

Embora Silvana tenha vivenciado uma infância em meio a um contexto social e político de grandes restrições no país - período da ditadura civil/militar (1964 -1985) -, isso não afetou diretamente sua vida naquele momento. $\mathrm{O}$ fato de morar em uma cidade pequena, do

3 Entrevista concedida por Silvana Vilodre Goellner aos autores, em 25 de outubro de 2019, na cidade de Alagoinhas/ Bahia.

4 Ibidem.

5 Etapa de ensino atualmente denominada de Ensino Médio e regulamentada pela Lei de Diretrizes e Bases da Educação Nacional (LDB), no 9394, de 31 de dezembro de 1996. 
interior, talvez tenha feito com que as notícias e as medidas de repressão chegassem até ali em menores proporções.

No entanto, a infância vivida no interior não limitou o seu olhar para as questões nacionais, pois, à medida que o tempo foi passando, sua sensibilidade para as questões sociais do país foram se desenvolvendo de forma a atingir o seu ápice durante a vida universitária, marcando a sua maneira de dialogar com o efervescente campo intelectual da Educação Física, na década de 1980.

\section{A formaÇão aCadÊMiCa de Silvana E o "RACHA” NA EDUCAÇão física}

Embora a entrevistada evidencie momentos felizes, de brincadeiras e diversão na sua infância em meados da década de 60, vale ressaltar que naquele momento, o país iniciava o período da ditadura militar, marcado por muitas mortes, repressões e perseguições em todos os setores da sociedade, inclusive na educação. No entanto, ela não tinha essas percepções no momento em que tudo acontecia, isso só foi acontecer durante as aulas de história, quando já estava no segundo grau. Dessa forma, começou a estudar a ditadura militar que estava acontecendo no Brasil e que naquele momento, prestes a entrar na graduação, em meados da década de 80 , já estava chegando ao fim.

Mesmo não percebendo diretamente os reflexos do que ocorria em sua época, Silvana Goellner relembra os jogos da copa do mundo de futebol de 1970, que assistiu ao lado de toda a sua família. Naquele momento, o futebol já tinha um papel político e social muito grande. Pereira $(2012)^{6}$, traz questões importantes acerca da utilização do futebol e do sucesso da seleção daquele ano para a promoção do governo, que não economizou no investimento à seleção canarinho. $\mathrm{O}$ futebol tinha todos os holofotes e tirava a atenção do regime ditatorial que a população brasileira estava vivendo (PEREIRA, 2012).

Quando entrou no curso de Educação Física, Goellner já estava mais consciente sobre o regime militar e não demorou muito para fazer parte do Diretório Acadêmico. Nessa mesma época, o país passava pelo movimento das Diretas Já ${ }^{7}$ e começaram discussões dentro do curso, referentes à sua relação com as ciências biológicas e as ciências humanas, denominado por Silvana como um "racha" na Educação Física, que até então possuía uma vertente epistemológica predominantemente biológica. Sobre sua passagem pelo Diretório Acadêmico e essa série de acontecimentos a depoente relata:

[...] mesmo quando eu estava morando em Carazinho, eu era muito ligada nas coisas assim, eu vi que tinha algum desconforto, um conservadorismo que me incomodava. Mas só fui perceber, quando eu entrei no diretório acadêmico, quando a gente estava passando pelo movimento pelas eleições diretas, o "assassinato" do Tancredo que naquela época a gente tinha a plena convicção que tinha sido assassinado. Na Educação Física com aquele "racha" que tinha naquele período, então Santa Maria foi palco de debates maravilhosos. Como era referência e Santa Maria é uma cidade muito militarizada, tem uma Base Aérea do lado da

6 Neste estudo intitulado Pra Frente Brasil: Ditadura militar, identidade e copa de 70, a autora busca retratar o período violento da ditadura e as relações estabelecidas com o futebol enquanto papel político e social na coletividade a partir da leitura de dois filmes: Pra frente Brasil e $O$ ano que meus pais saíram de férias. Para mais detalhes, ver: Pereira (2012). 7 Movimento civil de reivindicação por eleições presidenciais diretas no Brasil, ocorrido entre 1983 e 1984. A possibilidade de eleições diretas para a Presidência da República no Brasil se concretizaria com a votação da proposta de Emenda Constitucional Dante de Oliveira pelo Congresso. Entretanto, a Proposta de Emenda Constitucional foi rejeitada, frustrando a sociedade brasileira. Ainda assim, os adeptos do movimento conquistaram uma vitória parcial em janeiro do ano seguinte quando Tancredo Neves foi eleito presidente pelo Colégio Eleitoral. 
universidade, a gente convivia com um polo de esquerda e um polo de direita muito claro, a gente vivenciava muito isso, e no diretório a gente teve a chance de ter o Lino Castellani indo a Santa Maria ${ }^{8}$

Os fragmentos de memória presentes na fala da entrevistada possibilitam uma reflexão acerca de alguns aspectos. Um deles se refere à morte de Tancredo Neves, candidato à presidência em 1985 e que, perante a história oficial, embora tenha sido eleito, não chegou a tomar posse devido a problemas de saúde, que, posteriormente, o levou à morte por complicações cirúrgicas. No entanto, o depoimento de Silvana chama atenção para a existência de outras memórias não oficializadas que entram em disputa com a história oficial e que entendem esse contexto como um atentado político que resultou no assassinato de Tancredo Neves.

O procedimento metodológico da história oral prevê, entre outras características, a cautela e a vigilância que os pesquisadores(as) precisam ter no que diz respeito às produções da memória construídas pelos entrevistados(as); as versões dos fatos podem não corresponder necessariamente com as versões históricas oficiais, contudo, estas são construções cognitivas que os(as) entrevistados(as) acreditam ter ocorrido, portanto, são representações produzidas no tempo presente.

Segundo uma matéria divulgada pelo site do jornal $O G l o b o^{9}$, essa ideia tomou força após declaração do general Newton Cruz de que Paulo Maluf, adversário de Tancredo em 1985, teria proposto um golpe caso seu oponente fosse eleito. Nesse sentido, embora as notícias oficiais vinculassem a morte de Tancredo a problemas de saúde, memórias marginalizadas foram surgindo em oposição.

Outro aspecto presente nos depoimentos de Silvana trata-se do ideário de "racha" na Educação Física que, segundo ela, envolveu discussões de grande relevância para a construção da sua história e do seu processo de formação docente. As relações políticas nesse meio eram evidentes $\mathrm{e}$ "[...] as pessoas mais ligadas a esquerda eram das áreas humanas"10, se tornando um marcador para a sua própria trajetória acadêmica, deixando de lado as questões do treinamento esportivo e físico e se aproximando dessas novas discussões presentes na cidade de Santa Maria - polo de um grupo de pessoas que se tornaram referência na área de Educação Física relacionada às ciências humanas.

Ao ser questionada acerca da influência do currículo para sua aproximação com as discussões voltadas à área de humanas, a professora relata que não estavam consolidadas no currículo da instituição nem mesmo ligadas a professores. Para a entrevistada, essa construção foi determinada pela conjuntura vivenciada naquele momento, principalmente com sua ligação aos movimentos sociais. No seu relato abaixo, podemos notar de forma mais detida como as ações organizadas pelo diretório acadêmico contribuíram para esse contexto:

No currículo não tinha, eu acho que o que foi determinante foi a conjuntura da época, que era ir pra rua, era a morte do Tancredo, era a Diretas Já, o nascimento do PT no nas cidades do interior, os movimentos contra o aumento da passagem do ônibus dos estudantes, a

8 Entrevista concedida por Silvana Vilodre Goellner aos autores em 25 de outubro de 2019, na cidade de Alagoinhas/ Bahia.

9 RELEMBRE as teorias da conspiração sobre a morte de Tancredo Neves. In: O Globo.

10 Entrevista concedida por Silvana Vilodre Goellner aos autores em 25 de outubro de 2019, na cidade de Alagoinhas/ Bahia. 
reivindicação da moradia estudantil. Então foi esse movimento digamos assim formador do que sou. Professores, eu tive alguns professores que influenciaram bastante a minha formação, mas não eram digamos, abertamente de esquerda, eram sensíveis a várias questões. ${ }^{11}$

Embora tenha construído uma trajetória de importantes discussões relacionadas às ciências humanas, foi possível notar em seus relatos que Goellner sempre esteve muito ligada a disciplinas técnicas da formação em Educação Física. Foi monitora e estagiária no laboratório de biomecânica, monitora do laboratório de aprendizagem motora, fez atividade voluntária com a terceira idade e também foi monitora de natação. Isso acontecia exatamente devido ao contexto em que estavam vivenciando, a Educação Física era totalmente voltada a áreas técnicas e, em meio a esse cenário, Silvana participava de discussões e debates sem se ausentar das práticas oferecidas pelo currículo da UFSM vigente no momento, como relata a seguir:

[...] bem aquele momento que a gente discutia a formação dos currículos, a gente estava saindo de um currículo que era absolutamente voltado para as questões mais técnicas, tecnicista da Educação Física e estávamos participando de outras discussões. ${ }^{12}$

Outro fato de grande influência em sua trajetória enquanto pesquisadora foi o contato com alguns professores durante sua graduação, a saber: Ingrid Becker, Rainer Hildebrandt, José Francisco Silva Dias e Marta de Salles Canfield. A entrevistada relatou que Ingrid Becker lecionava ginástica, mas o fazia de uma forma diferente, ela via a prática para além dos aspectos competitivos; já o professor Rainer Hildebrandt, outro professor da área ginástica, veio da Alemanha para o Brasil nos primeiros anos da década de 1980, como professor visitante do Centro de Educação Física e Desportos da UFSM. Hildebrandt, foi o propositor do que veio a se tornar no Brasil a "Concepção de Aulas Abertas na Educação Física"13, um método considerado inovador para o período e de grande importância para a história da Educação Física, sendo utilizado e estudado na atualidade.

O livro de Hildebrandt, inclusive, foi publicado durante sua estadia na UFSM como professor da turma de Silvana Goellner. As aulas desenvolvidas por ele eram totalmente diferenciadas, fundadas na teoria crítica da Escola Alemã de Frankfurt, que, naquele período, influenciou diversos professores brasileiros no chamado Movimento Renovador da Educação Física $(\mathrm{MREF})^{14}$. Sobre essas aulas a entrevistada traz o seguinte relato:

[...] a gente tinha aulas em uma floresta, um mato que tinha do lado dos prédios da Educação Física; a gente elaborava os materiais para as aulas, era todo um processo novo de aprender o movimento, para explorar as capacidades de movimentação, foi o céu! Tanto é que no livro do Rainer que ele publicou no Brasil, que se chama Concepções Abertas no Ensino da Educação Física, aparecem várias fotos da minha turma de graduação, da gente fazendo as atividades. $^{15}$

11 Ibidem.

12 Entrevista concedida por Silvana Vilodre Goellner aos autores em 25 de outubro de 2019, na cidade de Alagoinhas/ Bahia.

13 A Concepção de Aulas Abertas na Educação Física foi desenvolvida por Hildebrandt e Laging (1986), é um estilo metodológico em que professores e alunos preparam juntos as aulas e estabelecem os objetivos a serem atingidos. Para maiores informações sobre essa concepção, consultar a obra: HILDEBRANDT, R.; LAGING, R. Concepções abertas ao ensino da educação física. Rio de Janeiro: Livro Técnico, 1986.

14 Segundo Machado e Bracht (2016), pode ser entendido como um movimento que foi capaz de transformar pressupostos que orientavam a Educação Física na década de 80, os quais eram voltados para a aptidão física e esportiva. 15 Entrevista concedida por Silvana Vilodre Goellner aos autores em 25 de outubro de 2019, na cidade de Alagoinhas/ Bahia. 
O professor José Francisco Silva Dias ou "Juca”, como é chamado por Silvana Goellner, lecionava Gerontologia. No período em que nossa entrevistada cursava a graduação, esse professor iniciou um projeto com idosos em Santa Maria no qual, posteriormente, Silvana se tornou bolsista voluntária. O contato próximo entre Silvana e o professor Juca através desse projeto deixou uma influência positiva em trajetória acadêmica. Outro nome citado por Silvana foi o de Marta Canfield, sua professora de estágio na área de desenvolvimento motor. O trabalho de Canfield enfatizava a dimensão pedagógica da Educação Física e foi justamente com ela que Silvana publicou seu primeiro artigo científico. O contato com professores inspiradores e a conjuntura política vivenciada por Goellner durante sua formação demonstram o quanto o momento histórico lhe ofereceu possibilidades e de certa forma norteou a sua trajetória profissional, conforme veremos.

\section{“O TEMA TEM QUE CORRER NA VEIA”: A IMPORTÂNCIA E A CONTRIBUIÇÃO DE SUA HISTÓRIA DE VIDA PARA O ESTUDO DAS MULHERES}

Durante a entrevista, Goellner relatou que ao se inscrever no curso de Educação Física sua intenção era ser treinadora de Voleibol, já que era um dos esportes que praticava, a ideia de ser professora não passava por sua cabeça. Porém, no primeiro semestre do curso, acabou se envolvendo com o diretório acadêmico e começou a ter outras visões sobre o que realmente queria.

Ao finalizar sua graduação na UFSM, cursou uma especialização em Pesquisa Curricular, ainda naquela instituição. No período em que se especializava, foi aberto o primeiro curso de mestrado de Ciências do Movimento Humano da UFRGS, no ano de 1989. Ao ter conhecimento disso, Silvana se candidatou e conseguiu fazer parte da primeira turma, dedicando sua pesquisa ao estudo da história da Educação Física com foco no método ginástico francês. Seus estudos deram origem a dissertação intitulada Método francês no Brasil: da caserna a escola, posteriormente publicada. Durante a entrevista, a pesquisadora relatou que pretende republicar essa pesquisa de forma atualizada com um olhar crítico sobre o atual contexto político $^{16}$ e social, marcado pela exigência de disciplina e ordem dentro do ambiente escolar. Ainda que tenha sido elaborada há décadas, essa discussão assume um lugar de relevância perante a sociedade atual.

Quando estava cursando o mestrado na UFRGS teve início a primeira gestão petista à frente da prefeitura de Porto Alegre. Esse fato resultou em um convite para que Silvana atuasse na coordenação dos centros comunitários da cidade, o que nossa entrevistada prontamente aceitou. Pouco tempo depois, já com o diploma de mestra em Educação Física nas mãos, Silvana participa de dois concursos, um para História da Educação Física na UFRGS e outro na área de ginástica na UFPel, em Pelotas - RS. Sendo aprovada em primeiro lugar nos dois certames, sua opção foi assumir a cadeira na UFRGS no ano de 1993, de onde só se desligou efetivamente em 16 de maio de 2019, devido ao processo de aposentadoria.

Seu doutoramento foi realizado na Universidade Estadual de Campinas (UNICAMP)

16 Com a ascensão de Jair Messias Bolsonaro à presidência, houve um retrocesso nas políticas sociais e ambientais implementadas pelos seus antecessores. Exemplo desse retrocesso é o nível de desmatamento que teve um aumento de 29,54\% em relação ao ano anterior, bem como a crescente consolidação de parcerias entre unidades escolares e polícia militar, instituindo unidades escolares cívico-militares. 
no ano de 1996, três anos após sua entrada para o corpo docente da ESEF-UFRGS. Foi justamente no doutorado que Silvana começou a trabalhar com aquele que se tornaria o tema de maior destaque em sua carreira acadêmica, a temática das mulheres, em suas palavras: “[...] em 1996 eu saí pra fazer o doutorado na UNICAMP, fiz na Faculdade de Educação já trabalhando mais especificamente com o tema das mulheres" ${ }^{17}$

Silvana inicia seus estudos sobre gênero com o desejo de estudar mulheres do esporte, mas como na época havia poucos nomes na área, decidiu iniciar sua pesquisa pela nadadora Maria Lenk. Sua motivação era guiada pelo fato de que Lenk possuía uma trajetória com uma série de momentos marcantes, como o fato de ter sido a primeira mulher a assumir o cargo de diretora da Escola de Educação Física e Desportos - EEFD da Universidade Federal do Rio de Janeiro - UFRJ, além de ter sido participante da primeira turma de Educação Física de professores civis, dentre outros aspectos. No entanto, ao aprofundar nos estudos, não achou interessante manter o protagonismo para quem já se constituía parte da história oficial. Foi então que decidiu dar visibilidade a outras mulheres e começou a pesquisar a Revista Educação Physica, como aponta:

\begin{abstract}
Na verdade, eu ia trabalhar com a história da Maria Lenk (da nadadora), meu projeto inicial foi a história da Maria Lenk. Mas quando eu comecei analisar um pouco e tive acesso a ela e a alguns documentos, eu vi que protagonizar a Maria Lenk era invisibilizar outras mulheres porque não era só a Maria Lenk. Focar só nela era meio que reproduzir uma história oficial de novo, e eu não queria fazer isso. Daí eu comecei a procurar as mulheres e eu resolvi analisar esta presença na primeira revista de Educação Física que circulou no Brasil. Que imagens de mulheres passavam ali? Daí trabalhei com essa lógica das mulheres e do esporte. ${ }^{18}$
\end{abstract}

Ao pesquisar as imagens presentes na Revista Educação Physica, começou a perceber questões relacionadas às representações higienistas. Sobre esse fato, Goellner afirma:

\begin{abstract}
E comecei a olhar as imagens dessa revista e comecei a perceber que tinha ali uma representação muito higienizada das pessoas, sobretudo das mulheres. Então as imagens que a Revista Educação Physica trazia eram imagens nazistas mesmo, que eu só fui descobrir quando tive a "sacação" de olhar aquilo em outras fontes. As mulheres que apareciam na Revista que eram sempre lindas, loiras, sorridentes. E pensei: de onde vem essas imagens? Não eram imagens brasileiras, de pessoas do Brasil. Eu consegui perceber duas grandes influências, uma era o cinema americano que estava entrando na América Latina e as imagens mostravam coreografias, as imagens de ginástica, por exemplo, eram todas coreografadas. A outra era uma estética 'racializada', com inspiração na Alemanha nazista. ${ }^{19}$
\end{abstract}

Para a professora, algo marcante para o estudo das imagens da Revista Educação Physica foi quando conseguiu o livro de Leni Riefenstahl ${ }^{20}$ contendo fotografias que divulgavam a estética nazista. Através desse livro, constatou-se que muitas das imagens presentes na revista estavam relacionadas ao nazismo. Nesse momento, foi possível perceber, na fisionomia da professora, que aquilo foi uma grande descoberta que contribuía para o entendimento de diversos fatores sociais:

17 Entrevista concedida por Silvana Vilodre Goellner aos autores em 25 de outubro de 2019, na cidade de Alagoinhas/ Bahia.

18 Ibidem.

19 Entrevista concedida por Silvana Vilodre Goellner aos autores em 25 de outubro de 2019, na cidade de Alagoinhas/ Bahia.

20 Cineasta alemã, representante dos ideais da estética nazista. 
Eram imagens publicadas em textos que falavam sobre a Educação Física nos Estados Unidos mas aparecia uma praça na qual se enxergava uma suástica. Muitas das imagens eram da própria Leni mas seu nome nunca aparecia. A Revista também fez a divulgação do livro do Hitler, Mein Kampf, publicava textos que ressaltavam a importância da Educação Física desenvolvida na Alemanha nazista. ${ }^{21}$

Sem perder o viés histórico, Goellner finaliza o doutorado, retorna para a UFRGS e se junta ao Centro de Memória do Esporte dessa instituição, vindo a desvincular-se da coordenação apenas no ano de 2019. As discussões e levantamentos de dados históricos realizados por ela se tornaram de grande importância para o processo constitutivo da Educação Física no campo das Ciências Humanas.

O envolvimento com a história da Educação Física se deu desde a sua pesquisa de mestrado, no entanto, esse caminho foi se estreitando para algo mais específico, relacionado à presença da mulher no meio esportivo e às contribuições históricas deixadas por elas nesse campo. Ao questionar como se deu essa forma um tanto particular de estudar a história da Educação Física, ela se recorda de sua relação com o Colégio Brasileiro de Ciências do Esporte $(\mathrm{CBCE})^{22}$, que lhe deu condições para criar meios de discutir a história pelo viés que já vinha lidando.

O CBCE realiza a cada dois anos um evento denominado Congresso Brasileiro de Ciências do Esporte (CONBRACE) ${ }^{23}$ e foi em um desses eventos, mais especificamente em Florianópolis no ano de 1999, que Silvana ajudou a criar um Grupo Temático (GT) de memória, já que não poderia criar o de história por ser disciplinar. Embora o GT fosse de memória, ela e outros idealizadores sabiam que nesse grupo teriam condições para discutir a história. O tema do evento naquele ano foi a questão do corpo, o que se tornou uma ótima oportunidade para debater sobre as questões das mulheres e promover importantes discussões acerca do corpo feminino.

Essas discussões foram levantadas também na própria UFRGS, como pode ser visto a seguir: "[...] no nosso programa, na UFRGS, dentro da subárea Representação Social do Movimento Humano eu fazia sempre uma discussão de gênero, o campo do esporte e das práticas corporais". ${ }^{24}$

Nessa sua trajetória de estudos sobre a história das mulheres eram necessários editais que auxiliassem nas pesquisas. Houve momentos em que as respostas a essas solicitações consideravam o tema como não tendo tanta relevância. Nesses casos, a professora rebatia justificando seus pedidos com o fato da carência de fontes nessa área e que seus estudos poderiam auxiliar nesses aspectos. Essa foi uma das mais importantes formas de conseguir

21 Entrevista concedida por Silvana Vilodre Goellner aos autores em 25 de outubro de 2019, na cidade de Alagoinhas/ Bahia.

22 O Colégio Brasileiro de Ciências do Esporte (CBCE) é uma entidade científica que agrega pesquisadores ligados à área de Educação Física/Ciências do Esporte. Organizado em Secretarias Estaduais e Grupos de Trabalhos Temáticos, liderados por uma Direção Nacional, possui representações em vários órgãos governamentais, é ligado à Sociedade Brasileira para o Progresso da Ciência e está presente nas principais discussões relacionadas à área de conhecimento. 23 É o evento científico nacional do Colégio Brasileiro de Ciências do Esporte, realizado a cada dois anos, está entre os principais do país. Além disso, são realizados periodicamente congressos estaduais e/ou regionais, bem como encontros dos Grupos de Trabalho Temáticos, sempre de elevada importância e contando com ampla participação da comunidade acadêmica.

24 Entrevista concedida por Silvana Vilodre Goellner aos autores em 25 de outubro de 2019, na cidade de Alagoinhas/ Bahia. 
esses editais e promover contribuições significativas para a Educação Física e o campo de discussões de gênero.

Embora tenha se dedicado a falar sobre a presença de mulheres de maneira bem ampla nos esportes, Silvana se recorda de momentos específicos de aproximação com a história das mulheres no futebol. O interesse surgiu quando o Ministério do Esporte a convidou para fazer uma discussão sobre gênero no Programa Segundo Tempo ${ }^{25}$ e ela começou a observar uma série de fatores que envolvia aquele projeto:

\begin{abstract}
[...] 30\% das pessoas que participavam das atividades eram meninas; $70 \%$ eram meninos. Quando eu vi estes dados do Segundo Tempo eu perguntei se havia uma política de inclusão de meninas para tentar reverter esse quadro. Porque muitas das atividades aconteciam no horário em que elas estavam em casa ajudando a cuidar dos irmãos mais jovens ou assumindo as tarefas domésticas, portanto, tinha que pensar o horário diferente ou ainda que tipo de atividade estava sendo ofertada. "Por que as meninas não estão aderindo ao Programa?" eu perguntei. Eu fazia muito essa crítica e me convidaram para fazer uma fala sobre as questões de gênero. Esta fala foi bem sucedida, eu a fiz em todos os eventos de formação que o Programa Segundo Tempo fez nas diversas regiões do país. ${ }^{26}$
\end{abstract}

Questões como essas são importantes para o processo reflexivo acerca de situações presentes em nosso cotidiano. As mulheres passam por dificuldade de inserção nos diferentes espaços da sociedade, como o meio esportivo, o mercado de trabalho, atividades de lazer, dentre tantas outras limitações decorrentes da visão histórica das obrigações familiares que lhes são impostas socialmente.

Outra situação específica para o processo de envolvimento com os estudos de mulheres no futebol partiu também de um convite do Ministério do Esporte para participar, no Rio de Janeiro, de um evento que pretendia discutir empoderamento de meninas por meio do futebol. Nesse evento, havia meninas de diversos países, reunidas por meio de uma conversa informal conduzida pela professora Silvana e por duas jogadoras de futebol profissional, a Aline Pellegrino e a Caitlin Fisher. A primeira, atuante por muito tempo na seleção brasileira e a segunda jogadora dos Estados Unidos, que veio tentar uma vaga no Santos Futebol Clube.

Nesse mesmo evento, Goellner percebeu que entre ela e as duas jogadoras havia muitas ideias em comum e, pouco depois, começaram a dialogar sobre as questões de gênero no futebol a partir de um projeto desenvolvido pelas jogadoras, denominado Guerreiras Project ${ }^{27}$.

Foi a partir desse contato com Aline Pellegrino, no evento sobre empoderamento, que Silvana começou a coletar informações que, futuramente, se transformaria em um trabalho sobre a história desta e de outras jogadoras como a Sissi ${ }^{28}$; o trabalho de Goellner teve grande importância para o processo de visibilidade da presença feminina no futebol (e no sistema

25 O Programa Segundo Tempo (PST) padrão é desenvolvido pela Secretaria Nacional de Esporte, Educação, Lazer e Inclusão Social, da secretaria Especial do Esporte do Ministério da Cidadania, o qual visa oferecer atividades de múltiplas vivências esportivas para estudantes de diversas faixas etárias, no contraturno escolar. O programa é dividido em três vertentes: Padrão - crianças e adolescentes de 6 a 17 anos; Paradesporto - pessoas com deficiência a partir de 6 anos de idade; e Universitário - discentes de universidades.

26 Entrevista concedida por Silvana Vilodre Goellner aos autores em 25 de outubro de 2019, na cidade de Alagoinhas/ Bahia.

27 Esse coletivo foi criado em 2010 e é formado por atletas, artistas, acadêmicos/as e ativistas que desenvolvem oficinas, pesquisas, performances e exposições visando estimular a justiça de gênero e empoderar mulheres no esporte e fora dele.

28 Cf. Goellner (2019). 
segregativo em geral), além de se estender a outros esportes.

Todo esse percurso acadêmico e científico de envolvimento com estudos de mulheres é resultante dos contextos vivenciados por Goellner durante sua infância; o fato de ter sido criada pela mãe e vê-la, mesmo fragilizada, assumir toda aquela responsabilidade de cuidar dos filhos e do sustento da casa, a influenciou veementemente na vida pessoal e profissional. Relacionado a isso, na época que iniciou a graduação, a Educação Física era comandada por médicos e por militares e a figura das mulheres não era muito presente, isso a incomodava exatamente por ter sido criada com uma referência feminina.

Portanto, abordar questões de gênero é muito mais que falar sobre mulheres, "Primeiro o tema tem que correr na veia. ${ }^{29 "}$

\section{CONSIDERAÇõES FINAIS}

Construir uma perspectiva de estudos direcionada à história de vida da professora Silvana não foi uma tarefa simples, sua trajetória foi estabelecida em meio a muitos contextos importantes tanto para ela como para toda sociedade. Traçar essa análise permitiu um novo olhar sobre seus estudos que hoje são discutidos dentro da área de Educação Física, evidenciando suas contribuições científicas de um ângulo diferente, a partir das suas escolhas, contextos e possibilidades.

Ter vivenciado a perda do seu pai na infância se tornou algo marcante durante toda a vida, o que refletiu em suas escolhas quando adulta. $O$ papel de sua mãe diante da família desestruturada fez com que surgisse uma representação da figura feminina vinculada à força, à luta e à determinação. Esse fator contribuiu para sua escolha de estudar questões relacionadas às mulheres. Seus estudos se voltaram para os aspectos sociais e políticos que envolvem a área de Educação Física, bem como os estudos sobre gênero, percebendo a mulher pouco evidenciada na sociedade.

Vale ressaltar que a formação acadêmica dessa professora aconteceu em um momento marcante para a Educação Física; surgiram muitas discussões que se tornaram essenciais para o seu processo de consolidação nas áreas sociais e humanas. Isso ocorreu diante a conjuntura social e política vivenciada no país em meados da década de 1980, período final do regime militar, em que muitos professores se sentiram incomodados com a forma com que o governo nacional tratava a Educação Física, construindo novas linhas de debates que iam de encontro a utilização dessa disciplina como um meio de manipulação social.

Esse cenário se tornou fundamental para que Silvana construísse uma trajetória de debates e discussões científicas no campo das ciências humanas, voltando seu olhar para as questões referentes às lutas das mulheres por visibilidade e por reconhecimento, principalmente, no meio esportivo. Seu pioneirismo e história de vida enquanto mulher e pesquisadora deixaram um legado que atinge desde seus/suas orientandos(as) até outros alunos(as) e pesquisadores(as), que se inspiram em sua trajetória acadêmica, científica e social. Essas contribuições atingiram diretamente o campo da Educação Física, se tornaram referência nos estudos de mulheres, além de terem auxiliado na difusão de debates e problemáticas afins.

29 Entrevista concedida por Silvana Vilodre Goellner aos autores em 25 de outubro de 2019, na cidade de Alagoinhas/ Bahia. 


\section{REFERÊNCIAS BIBLIOGRÁFICAS}

ALBERTI, V. Histórias dentro da História. In: PINSKY, Carla Bassanezi, (org.). Fontes Orais. São Paulo: Contexto, 2005, p. 155-202.

ALTMANN, H.; FERNANDES, S. C. Mulher e esporte: palavras iniciais sobre os desafios ao ensino na escola. POIÉSIS. Unisul, Tubarão, v.8, n.13, p. 126 - 140, Jan/Jun 2014.

ANJOS, L. A.; JORAS, P. S.; RAMOS, S. S.; GOELLNER, S. V. Guerreiras Project: futebol e empoderamento de mulheres. Revista estudos feministas, v. 26, p. 1-12, 2018.

BRASIL. Ministério da Cidadania. Segundo Tempo. Última atualização em 15 de agosto de 2019. Disponível em: http://arquivo.esporte.gov.br/index.php/institucional/esporte-educacao-lazer-einclusao-social/segundo-tempo. Acesso em: 12 maio 2020.

BOSI, E. O tempo vivo da memória: ensaios de psicologia social. São Paulo: Ateliê Editorial. 2003.

GOELLNER, S. V.; KESSLER, C. S. A sub-representação do futebol praticado por mulheres no Brasil. Revista USP, p. 31-38, 2018.

GOELLNER, S. V. Sissi, a Imperatriz: entrevista com Sisleide Lima do Amor. FuLiA / UFMG, v. 4, p. $117,2019$.

HILDEBRANDT, R.; LAGING, R. Concepções abertas ao ensino da educação física. Rio de Janeiro: Livro Técnico, 1986.

KESSLER, C. S; COSTA, L. M. da; PISANI, M. da S. (Org.). As mulheres no universo do futebol. Editora UFSM, Santa Maria - RS, 2020.

MACHADO, T. S.; BRACHT, V. O impacto do Movimento Renovador da Educação Física nas identidades docentes: uma leitura a partir da "teoria do reconhecimento" de Axel Honneth. Movimento, Porto Alegre, v. 22, n. 3, 849-860, jul./set. de 2016.

MORAES, E. V. As mulheres também são boas de bola: histórias de vida de jogadoras baianas (1970-1990). Tese (Doutorado em História) - Pontifícia Universidade Católica de São Paulo, São Paulo, 2012.

OLIVEIRA, C.S. Mulheres em quadra: o futsal feminino fora do armário. Campo Grande, 2008.

PEREIRA, C. K. Pra Frente Brasil: Ditadura militar, identidade e copa de 70. Universidade Federal do Rio Grande do Sul. Faculdade de Biblioteconomia e Comunicação. Departamento de Comunicação: Especialização em Jornalismo Esportivo, 2012. Disponível em: https://www.lume. ufrgs.br/bitstream/handle/10183/94461/000913882.pdf?sequence=1. Acesso: maio 2020.

PERROT, M. Minha história das mulheres. Trad. Ângela M. S. Corrêa. 2.ed., $6^{a}$ reimpressão. São Paulo: Contexto, 2019.

PORTELLI, A. Tentando aprender um pouquinho. Algumas reflexões sobre a ética na História Oral. São Paulo: Projeto História, 1997.

RELEMBRE as teorias da conspiração sobre a morte de Tancredo Neves. In: O Globo. Matéria disponível em: https://oglobo.globo.com/cultura/relembre-as-teorias-da-conspiracaosobre-morte-de-tancredo-neves-23057397. Acesso em: 30 out. 2021. 


\section{Fonte ORAL}

GOELLNER, Silvana Vilodre. [Entrevista cedida aos autores/pesquisadores]. Alagoinhas-BA, 25 de outubro de 2019. 